\title{
Alimentos funcionais: benefícios proporcionados à saúde, destacando o consumo de alimentos probióticos
}

\section{Functional foods: benefits provided to health, featuring the consumption of probiotic foods}

\author{
Daiane Albuquerque Ribeiro Reis Silva ${ }^{1}$, Brendon Maximiliano Oliveira da Silva ${ }^{2}$, \\ Ismael Maciel de Mancilha ${ }^{3}$, Aline Francisca de Souza ${ }^{4 *}$ \\ ${ }^{1}$ Discente do Curso de Graduação em Biologia do Centro Universitário Teresa D’Ávila - UNIFATEA, Lorena, SP. \\ ${ }^{2}$ Discente do Curso de Graduação em Biologia do Centro Universitário Teresa D’Ávila - UNIFATEA, Lorena, SP. \\ ${ }^{3}$ Doutor e docente da Escola de Engenharia de Lorena - EEL/USP, Lorena, SP. \\ ${ }^{4}$ Doutora e docente do Centro Universitário Teresa D’Ávila - UNIFATEA, Lorena, SP.
}

\begin{abstract}
Resumo
A alimentação saudável fornece fontes de micro e macronutrientes necessários para o funcionamento adequado do organismo. Porém, nas últimas décadas, o alimento parou de ter apenas a função nutricional básica e passou a ser considerado como fonte de proteção à saúde. Certos alimentos, considerados alimentos funcionais, podem estimular o metabolismo, melhorando o funcionamento do organismo, prevenindo o surgimento de determinadas doenças, proporcionando o bem-estar aos indivíduos e promovendo benefícios à saúde. Entre os alimentos funcionais estão fibras alimentares, pré-bióticos e probióticos. O consumo de alimentos probióticos vem aumentando consideravelmente, porém a viabilidade celular desses micro-organismos, característica necessária para o efeito benéfico no organismo do consumidor, pode ser afetada por alguns fatores, como processamento do alimento, tempo de armazenamento e até mesmo o pós consumo, ao entrar em contato com as condições adversas encontradas no trato gastrointestinal. Dessa forma, o presente trabalho realizou uma revisão bibliográfica em publicações científicas para abordar o tema alimentos funcionais, suas características e benefícios, ressaltando os micro-organismos probióticos e as técnicas de microencapsulamento que promovem aumento da viabilidade de tais alimentos funcionais.
\end{abstract}

Palavras-chave: qualidade de vida, probióticos, pré-bióticos, fibras alimentares.

\begin{abstract}
Healthy food provides sources of micro and macro nutrients necessary for the proper functioning of the body. However, in the last decades, the food stopped having only the basic nutritional function and came to be considered as a source of health protection. Certain foods, considered functional foods, can stimulate metabolism, improve the body functioning, prevent the onset of certain diseases, provide individual well-being and promote health benefits. Among the functional foods are dietary fibers, prebiotics and probiotics. The consumption of probiotic foods has increased considerably, but the cellular viability of these microorganisms, a necessary characteristic for the beneficial effect in the consumer's body, can be affected by factors such as food processing, storage time and even after consumption, like adverse conditions of the gastrointestinal tract. Therefore, the present work carried out a bibliographic review of scientific publications to address the subject of functional foods, their characteristics and benefits, highlighting probiotic microorganisms and microencapsulation techniques that promote the viability of such functional foods.
\end{abstract}

Keywords: quality of life, probiotics, prebiotics, dietary fibers.

\footnotetext{
*Doutora e docente do Centro Universitário Teresa D’Ávila-UNIFATEA, Lorena, SP, Email: alinefsmga@ gmail.com, Fone: (12) 98269-4278
}

Recebido em: 07/Aug/2017

Aceito em: 04/Abr/2018 


\section{Introdução}

O principal papel da dieta consiste em fornecer nutrientes suficientes para atender exigências metabólicas, dando ao consumidor uma sensação de satisfação e bem-estar. Porém, nas últimas décadas, o alimento deixou de ser visto apenas como veículo de nutrientes essenciais para garantir o crescimento e desenvolvimento adequado, passando a ser visto como ferramenta para promoção do bem-estar do indivíduo (GRANATO et al., 2010).

O alerta sobre os efeitos negativos do consumo de alimentos com altos teores de gorduras e açúcares começou na década de 1960. Na década de 1980 surgiram os alimentos diet e light, inseridos no mercado de consumo com sucesso. Entretanto, a exigência quanto à qualidade dos alimentos aumentou e a busca por alimentos que promovessem benefícios à saúde fez surgir, assim, os alimentos funcionais (RAUD, 2008).

Os alimentos funcionais são definidos como alimentos comuns com componentes fisiologicamente ativos que promovem benefícios para a saúde, além da nutrição básica, estando relacionados à redução do risco da manifestação de certas doenças (CARRARA et al., 2009). Além de apresentar efeitos nutricionais adequados, o alimento funcional afeta beneficamente uma ou mais funções no organismo, sendo relevante para o bem-estar e saúde, para a redução do risco de doenças, porém não podem ser considerados medicamentos, uma vez que os princípios responsáveis pelos efeitos benéficos não são extraídos do alimento (ZERAIK et al., 2010).

Os principais alimentos funcionais são probióticos, pré-bióticos, cereais funcionais, bebida funcional não alcoólica enriquecida, carnes contendo antioxidantes e ovos com baixos níveis de colesterol. Segundo O'Sullivan et al. (1992), os produtos de origem láctica contendo micro-organismos probióticos que estão no mercado são sorvetes, manteiga, iogurte, leite em pó e sobremesas congeladas. No entanto, a forma mais comum de administração de probióticos é por meio de produtos lácteos fermentados (OUWEHAND et al., 2002).

Indústrias alimentícias enfrentam sérios desafios com alimentos probióticos, relacionados à estabilidade e capacidade de sobrevivência dos micro-organismos durante o processamento, preservação e no período de armazenamento. Além disso, outra barreira que afeta a estabilidade dos probióticos é a passagem pelo trato gastrointestinal do consumidor, no qual existem condições adversas, extremamente ácidas, que podem diminuir a viabilidade dos micro-organismos e, consequentemente, a eficácia quanto aos benefícios proporcionados pelo seu consumo (MANDAL; HATI, 2016). A aplicação da técnica de microencapsulação pode melhorar significativamente a estabilidade dos probióticos durante o processamento e armazenamento, bem como durante a passagem desses alimentos pelo trânsito gastrointestinal. Diante disso, o presente trabalho realizou uma revisão bibliográfica em publicações científicas para abordar o tema alimentos funcionais, suas características e benefícios, ressaltando os micro-organismos probióticos e as técnicas de microencapsulamento que promovem aumento da viabilidade de tais alimentos funcionais.

\section{Alimentos funcionais}

O conceito alimento funcional foi sugerido pela primeira vez em 1984 por cientistas japoneses que estudaram as relações entre nutrição, satisfação sensorial, fortificação e modulação do sistema fisiológico. Foi a partir do interesse dos japoneses por alimentos funcionais que se iniciou a consciência para a necessidade de tais produtos na Europa e Estados Unidos, com a finalidade de reduzir os custos dos cuidados com a saúde da população (SIRO et al., 2008). Moraes e Colla (2006) relatam que outro fator que contribuiu para o desenvolvimento dos alimentos funcionais foi o aumento da consciência dos consumidores que, visando melhoria da qualidade de vida, começaram a optar por hábitos saudáveis.

De acordo com Ibañes e Cifuentes (2013), o Ministério da Sáude, Trabalho e Previdência Social do Japão estabeleceu normas legais para a aprovação de alimentos para uso especificados na área da saúde (Foods for Specified Health Uses - FOSHU) em 1991. Nos Estados Unidos, a aprovação dos alimentos funcionais foi regulamentada pela Food and Drug Administration (FDA) incluindo vários produtos, como suplementos dietéticos, alimentos medicinais e aditivos alimentares. Enquanto que na Europa, após o apoio da Comissão Europeia sobre o estudo científico dos alimentos funcionais, sua definição foi modificada, considerando-se funcional apenas o alimento que em conjunto com a função nutricional apresente efeitos benéficos sobre uma ou mais funções do organismo humano, ou que atue nas condições físicas gerais, diminuindo o risco da evolução de doenças. 
No Brasil, a definição de propriedade funcional em alimentos foi realizada pela Agência Nacional de Vigilância Sanitária (Anvisa), nas resoluções Anvisa, n. 18 e 19 de 30/4/99 (BRASIL, 1999). Foi estabelecido que alimentos ou ingredientes com propriedades funcionais, devem apresentar, além da função nutricional básica, efeitos metabólicos e/ou fisiológicos benéficos à saúde. De acordo com a Anvisa (BRASIL, 2008), os alimentos funcionais atuam na manutenção geral da saúde e na prevenção dos riscos de doenças, sendo seguros para o consumo sem a supervisão médica. Assim, o consumo desses alimentos deve reduzir o risco de doenças e não devem ser referidos como alimentos para tratamento ou a cura de doenças.

Alguns cereais podem ser considerados alimentos funcionais (MATTA et al., 2012), proporcionando benefícios à saúde; cereais também podem ser utilizados como substrato fermentável para crescimento de microrganismos probióticos, assim denominados alimentos ou ingredientes pré-bióticos.

Segundo Karkow et al. (2007), os ingredientes pré-bióticos são constituídos principalmente por carboidratos que não são absorvidos pelo intestino delgado do consumidor, sendo seletivamente fermentados por bactérias endógenas, auxiliando o crescimento e metabolismo de probióticos (NETTO, 2009; REIS et al., 2016). Os pré-bióticos podem atuar na inibição da multiplicação de patógenos, proporcionando benefícios adicionais à saúde do hospedeiro (SAAD, 2006). Assim, esses produtos alimentares apresentam grande potencial para manutenção equilibrada da microbiota intestinal, visando a saúde e o bem-estar do consumidor (GIBSON et al., 2004).

\section{Fibras alimentares como alimentos funcionais}

Fibras alimentares são definidas como as porções das plantas resistentes à ação das enzimas digestivas de humanos, incluindo polissacarídeos e lignina (ANDERSON et al., 2009). De acordo com Burton-Freeman (2000), as fibras alimentares não são hidrolisadas e absorvidas no estômago e intestino delgado. No intestino grosso, as fibras atuam como substrato para a microbiota intestinal (PUUPPONEN-PIMIA et al., 2002). Dessa forma, os carboidratos não digeríveis são possíveis pré-bióticos e, portanto, benéficos para a saúde dos consumidores (GRIZARD; BARTHOMEUF, 1999).

As recomendações de inclusão de fibra alimentar na dieta variam de acordo com a idade, o sexo e o consumo energético, sendo a quantidade adequada em torno de $14 \mathrm{~g}$ de fibra para cada $1.000 \mathrm{kcal}$ ingeridas. Assim, considera-se adequada a ingestão de $38 \mathrm{~g} /$ dia e $25 \mathrm{~g} /$ dia de fibras para homens e mulheres com idade entre 19 e 50 anos, respectivamente (INSTITUTE OF MEDICINE, 2005). Dhingra et al. (2012) sugerem o consumo entre $20 \mathrm{~g} /$ dia e $35 \mathrm{~g} /$ dia de fibra alimentar para adultos saudáveis.

Estudos revelam que o consumo adequado de fibras pode reduzir o risco do desenvolvimento de moléstias como doença arterial coronariana, acidente vascular cerebral, hipertensão arterial, diabetes mellitus, desordens gastrointestinais, como também atuar na melhoria dos níveis dos lipídeos séricos, no funcionamento do sistema imune e auxiliar na redução do peso corporal (BERNAUD; RODRIGUES, 2013).

As fibras alimentares podem ser encontradas em diversos grãos como arroz, trigo, aveia, ervilha, feijão (MORAES; COLLA, 2006), aveia (GUTKOSKI et al., 2007), em frutos, como banana verde (GUTKOSKI et al., 2007), maracujá (ZERAIK et al., 2010), entre outros.

A farinha de aveia (Avena sativa L.) tem se destacado entre profissionais da saúde e consumidores pelos benefícios nutricionais à saúde, principalmente por suas fibras alimentares. Dentre os benefícios proporcionados pela aveia destacam-se a redução do colesterol sanguíneo e prevenção de doenças cardiovasculares (GUTKOSKI et al., 2007). Em sua composição química encontramos proteínas, carboidratos, fibras, vitaminas, minerais, lipídeos, gordura insaturada e $\beta$-glucanas (ZAPATA et al., 2014). Estudos realizados por Karam et al. (2001) demonstraram a presença de $13,4 \%$ de proteína, $7,9 \%$ de lipídeos, $4,0 \%$ de fibra alimentar e $63 \%$ de carboidratos na farinha de aveia.

A farinha de arroz integral aos poucos vem substituindo a farinha de trigo por seu alto valor nutritivo, rico em proteínas, vitaminas, minerais e fibras. Além disso, apresenta menor risco de alergias alimentares, fator que vem beneficiando a população que apresentam alergia a determinados alimentos (MONTEIRO, 2013). Pesquisas realizadas por Walter et al. (2008), demonstram que a farinha de arroz integral possui em sua 
composição centesimal média $74,1 \%$ de amido total, $10,5 \%$ de proteínas, $2,5 \%$ de lipídeos, $8,9 \%$ de fibra insolúvel, 2,8\% de fibra solúvel e 11,8\% de fibra total. A celulose, hemiceluloses, amido resistente e pectinas são polissacarídeos que não são digeridos pelas enzimas no trato gastrintestinal e constituem parte da fração de fibra alimentar.

O sorgo (Sorghum bicolor L.) é um cereal que tem se destacado na alimentação humana (OLIVEIRA et al., 2015). Por não apresentar glúten em sua composição, tem substituído a farinha de trigo na fabricação de produtos de panificação para indivíduos que apresentam doença celíaca (FERREIRA et al., 2009). Estudos realizados por Macedo et al. (2016) indicam que a farinha de sorgo possui em sua composição centesimal $14,3 \%$ de proteínas, $69,2 \%$ de carboidratos e $3,1 \%$ de lipídeos. Além de ser fonte de carboidratos, o sorgo apresenta fibras, compostos bioativos e amido resistente (QUEIROZ et al., 2009). De acordo com Macedo et al. (2016), esse alimento contribui na redução de doenças crônicas como diabetes, obesidade e doenças cardiovasculares.

A banana (Musa spp) é fruta que está presente na dieta alimentar de quase toda população (RANIERI; DELANI, 2014). No fruto verde podem ser detectados compostos fenólicos e antioxidantes (SILVA et al., 2015a), com um considerável teor de amido resistente, porém a sua concentração difere de acordo com o genótipo da bananeira e a forma de manejo da planta (RAMOS et al., 2009). No trabalho realizado por Medeiros et al. (2010), em relação à composição centesimal média da farinha de banana verde, foram detectados 3,8\% de proteína, $0,9 \%$ de lipídeos, $83,3 \%$ de carboidratos, $0,5 \%$ de fibra bruta e valor calórico $(\mathrm{kcal})^{3}$ de $356,64 \%$, sendo o amido resistente o maior constituinte químico da farinha de banana verde, variando entre $55 \%$ a $93 \%$.

A farinha de banana verde apresenta em sua composição nutritiva amido, proteína, potássio, fósforo, magnésio, cobre, manganês e zinco, com sabor suave e coloração clara (CARMO, 2015; BORGES et al., 2009). O frequente consumo de farinha de banana verde pode auxiliar na prevenção de algumas doenças, dentre elas as cardiovasculares, diabetes tipo 2 e obesidade. A presença de alto teor de amido resistente caracteriza a farinha de banana verde como um alimento pré-biótico, que pode ser fermentado por micro-organismos benéficos no intestino delgado, melhorando o sistema imunológico e prevenindo infecções intestinais, inflamações e até mesmo o câncer intestinal (RANIERI; DELANI, 2014).

Maracujá é o nome popular de várias espécies do gênero Passiflora, porém, no Brasil, o maracujá-azedo ou amarelo (P. edulis flavicarpa) é o mais cultivado e comercializado pela qualidade de seus frutos. Diversos estudos relatam a presença de substâncias polifenólicas, ácidos graxos poli-insaturados e fibras na casca, semente e fruto, indicando o maracujá como alimento funcional. Os polifenóis, principalmente flavonoides, proporcionam ao maracujá ação antioxidante (ZERAIK et al., 2010).

Segundo Zeraik et al. (2010), os subprodutos provenientes do processamento do suco de maracujá correspondem a cerca de $65 \%$ a $70 \%$ da massa do fruto. Esse subproduto apresenta alto valor nutricional, sendo utilizado para consumo humano e animal. A casca, que pode ser utilizada para produção de farinha, contém niacina (vitamina $\mathrm{B}_{3}$ ), ferro, cálcio e fósforo e é rica em fibras solúveis como a pectina, que contribui para a prevenção de doenças cardiovasculares e gastrointestinais, câncer de cólon, diabetes e obesidade.

\section{Micro-organismos probióticos e os benefícios à saúde}

Os probiótico são alimentos funcionais definidos como micro-organismos vivos que afetam beneficamente a fisiologia do hospedeiro, trazendo benefícios à sua saúde (SOUZA, 2015). Entre os micro-organismos com propriedades probióticas estão as bactérias lácticas, como Lactobacilos, Bifidobactérias e Enterococos. Durante as últimas décadas, outras espécies e até leveduras foram descritas como potenciais probióticos (OUWEHAND et al., 2002), como demonstrado na tabela 1 .

Dentre os benefícios proporcionados pelo consumo de probióticos estão a prevenção da colonização intestinal por patógenos, tratamento e prevenção da diarréia (BRAGA et al., 2015), inibição do crescimento de micro-organismos patogênicos no intestino delgado, favorecendo a digestão e amenizando risco de tumores (VIDAL et al., 2012). Além disso, os probióticos também são usados na medicina humana, na regulação da microbiota intestinal e como imunomoduladores (MARTINS et al., 2005; COPPOLA; TURNES, 2004). 
Tabela 1. Micro-organismos utilizados em produtos probióticos.

\begin{tabular}{lll}
\hline \multicolumn{1}{c}{ Espécies de Lactobacillus } & \multicolumn{1}{c}{$\begin{array}{c}\text { Espécies de } \\
\text { Bifidobacterium }\end{array}$} & \multicolumn{1}{c}{ Outros } \\
\hline L. acidophilus & B. adolescentes & Escherichia coli \\
L. brevis & B. bifidum & Lactococcus lactis subsp. lactis e cremoris \\
L. casei & B. breve & Leuconostoc mesenteroides subsp. Dextranium \\
L. crispatus & B. infantis & Pediococcus acidilactici \\
L. delbrueckii subsp. Bulgaricus & B. lactis & Propionibacterium bacillus \\
L. fermentum & B. longum & Saccharomyces boulardii \\
L. helveticus & & Streptococcus lactis subsp. Thermophulus \\
L. plantarum & & \\
L. paracasei & & \\
L. reuteri & & \\
L. rhamnosus & & \\
L. salivarius & & \\
\hline
\end{tabular}

Fonte: adaptado de O’Sullivan et al. (1992) e Ouwehand et al. (2002).

Estudos demonstram que os probióticos competem com micro-organismos patógenos pelo sítio de adesão, modificando o ambiente intestinal. Os ácidos produzidos à partir do metabolismo dos probióticos resultam na redução do $\mathrm{pH}$, modificando as respostas inflamatórias e imunológicas (CARDARELLI, 2006; MORAIS; JACOB, 2006). Além da inibição do crescimento de micro-organismos patogênicos, os probióticos podem contribuir para o aumento da tolerância à lactose, a redução dos níveis de colesterol, a atividade anticarcinogênica e a estimulação do sistema imune (O'SULLIVAN et al., 1992).

Quando os probióticos são expostos ao suco gástrico, enzimas digestivas e sais biliares podem reduzir sua viabilidade. Isso ocorre devido ao baixo pH do estômago e a ação de enzimas digestivas como a pepsina, que proporcionam efeito protetivo contra a passagem de bactérias no trato gastrointestinal (OLIVEIRA, 2011). Assim, para um micro-organismo ser considerado probiótico, além de não ser patogênico, ele deve resistir ao baixo pH gástrico, a ação da bile, secreções pancreáticas e intestinais, bem como possuir capacidade de adesão ao trato gastrointestinal e de produção de substâncias antimicrobianas contra patógenos intestinais (BRAGA et al., 2015; SIMEONI et al., 2014).

\section{Microencapsulação de micro-organismos probióticos}

A redução da viabilidade celular de micro-organismos probióticos após a passagem pelo sistema gastrointestinal pode ser minimizada pela utilização da técnica de encapsulação em uma matriz polimérica (COOK et al., 2012). A técnica de microencapsulação baseia-se em recobrir partículas de interesse com um polímero, visando preservá-las, estendendo a vida útil do produto (SILVA et al., 2015b).

A microencapsulação oferece ao probiótico uma barreira física contra condições adversas encontradas no trato gastrointestinal. Após ingeridas, as microcápsulas liberam gradualmente o conteúdo encapsulado, proporcionando a sua função protetiva (ZOU et al., 2011; SIMEONI et al., 2014). De acordo com Krasaekoopt et al. (2003), a encapsulação de bactérias probióticas em alimentos lácteos pode aumentar a viabilidade celular durante a produção e armazenamento do produto.

A encapsulação tem como objetivo estabelecer uma barreira seletiva entre o micro-organismo e o ambiente externo, estabilizar o material interno, controlar as reações de oxidação, permitir a liberação controlada ou prolongada dos materiais encapsulados, mascarar sabores, cores ou odores e estender a vida útil (ANAL; SINGH, 2007). Essa técnica também protege as células das condições adversas do estômago, mantendo sua integridade até a chegada ao intestino (BRUN-GRAEPPI et al., 2011).

Dentre as técnicas usadas para encapsulamento de probióticos estão a coacervação, spray chilling, polimerização interfacial, cocristalização, extrusão, atomização (spray drying) e emulsificação cada uma delas resulta em microcápsulas com características morfológicas distintas e de tamanho variável (SIMEONI et al., 2014; MENEZES et al., 
2013; OLIVEIRA, 2013). Entre os polímeros utilizados na microencapsulação de bactérias estão gelatina, carregana, amido resistente, alginato e quitosana (BURGAIN et al., 2011; COOK et al., 2012; HUQ et al., 2013). O aumento da viabilidade celular, proporcionado pelo encapsulamento de micro-organismos probióticos durante o período de armazenamento e a exposição ao fluido gástrico simulado foi demonstrado em vários estudos (LI et al., 2011; SILVA et al., 2015a; CHAVARRI et al., 2010).

Experimentos realizados por Li et al. (2011) demonstram que a exposição de $L$. casei encapsulada em matriz polimérica de alginato e a combinação de alginato com quitosana ao fluido gástrico simulado (FGS) não afetou acentuadamente a viabilidade celular após 120 minutos - os micro-organismos apresentaram taxa de sobrevivência acima de $90 \%$ após o contato. Resultados promissores também foram obtidos por Chavarri et al. (2010), que demonstraram que a exposição de $B$. bifidum e L. gasseri encapsuladas em matriz polimérica contendo alginato ao FGS por 120 minutos acarretou na sobrevivência de $85 \%$ das células.

Silva et al. (2015a) avaliaram a sobrevivência de Bifidobacterium animalis e Lactobacillus acidophilus encapsuladas pelo método de spray drying durante o armazenamento e a passagem pelo trato gastrointestinal in vitro. Os resultados demonstram que as células encapsuladas permaneceram viáveis após 120 dias de armazenamento a $4{ }^{\circ} \mathrm{C}$ e $25^{\circ} \mathrm{C}$ e que a técnica de microencapsulação protegeu os micro-organismos das condições gastrointestinais simuladas. Em outros experimentos realizados por Silva et al. (2014), microcápsulas de Bifidobacterium animalis e Lactobacillus acidophilus foram adicionados à produção de salame tipo italiano. Os resultados demonstram que a adição das microcápsulas contendo as células probióticas não alterou as características físicoquímicas do salame e que os micro-organismos mantiveram-se viáveis após cerca de 50 dias.

Os experimentos realizados por ZammoraVega et al. (2012) visando o encapsulamento da levedura Saccharomyces boulardii pelo método de emulsificação utilizando inulina, alginato de sódio e mucilagem como polímeros de revestimento demonstraram maior viabilidade celular em células encapsuladas, quando comparadas a células livres. Após 35 dias de armazenamento, a levedura encapsulada apresentou $76,1 \%$ de viabilidade, enquanto que a célula livre apresentou apenas $63,3 \%$.

A análise da viabilidade de Bifidobacterium BB-12 encapsulada em leite desnatado reconstituído e inulina adicionadas ao iogurte foram avaliadas por Pinto et al. (2013). Os resultados demonstram que o micro-organismo encapsulado manteve a sua viabilidade celular após período de 90 dias de armazenamento a $-18{ }^{\circ} \mathrm{C}$. Esse experimento demonstrou que a aplicação de probióticos encapsulados contribuiu para a manutenção da viabilidade das células bacterianas durante o período de armazenamento.

\section{Considerações finais}

A saúde e o bem-estar estão diretamente relacionados com a alimentação saudável. O consumo de alimentos funcionais como fibras, ingredientes pré-bióticos e probióticos pode promover diversos benefícios para a saúde, como melhoria do funcionamento do organismo e prevenção de diversas doenças. Devido à sua composição, algumas fibras alimentares podem ser consideradas pré-bióticos, atuando na melhoria do fluxo intestinal, bem como no crescimento de probióticos. Para que os micro-organismos probióticos promovam benefícios à saúde do hospedeiro eles devem manter a integridade celular durante o armazenamento e após o consumo. Vários estudos demonstram que a viabilidade celular pode ser aumentada pelo encapsulamento dos micro-organismos probióticos em diferentes matrizes poliméricas. Dessa forma, a técnica de encapsulamento de probióticos pode ser considerada promissora para aplicações de micro-organismos em diversos tipos de alimentos.

\section{REFERÊNCIAS}

ANAL, K. A.; SINGH, H. Recent advances in microencapsulation of probiotics for industrial applications and targeted delivery. Trends in Food Science \& Technology, v. 18, p. 240-251, 2007.

ANDERSON, J. et al. Health benefits of dietary fiber. Nutrition Reviews, v. 67, p. 188-205, 2009.

BERNAUD, F. S. R.; RODRIGUES, T. C. Fibra alimentar - ingestão adequada e efeitos sobre a saúde do metabolismo. Arquivos Brasileiros de Endocrinologia \& Metabologia, v. 57, p. 397405, 2013. 
BORGES, A. M.; PEREIRA, J.; LUCENA, E. M. P. Caracterização da farinha de banana verde. Food Science and Technology, v. 29, p. 333-339, 2009.

BRAGA, A. V. et al. Resistência ao suco gástrico de bactérias lácticas isoladas de queijo minas padrão artesanal em minas gerais. In: $\mathrm{V}$ JORNADA ACADÊMICA INTERNACIONAL DE BIOQUÍMICA, 5., 2015, Divinópolis. Anais... São Paulo: Blucher, 2015. p. 79.

BRASIL. Ministério da Saúde. Agencia Nacional de Vigilância Sanitária - ANVISA. Resolução n ${ }^{\circ}$ 18, de 30 de abril de 1999. Aprova o Regulamento Técnico que estabelece as diretrizes básicas para análise e comprovação de propriedades funcionais e ou de saúde alegadas em rotulagem de alimentos, constante do anexo desta portaria. Diário Oficial [da] Republica Federativa do Brasil, Brasília, DF, 03 maio 1999.

BRASIL. Ministério da Saúde. Agencia Nacional de Vigilância Sanitária - ANVISA. IX - Lista de Alegações de Propriedade Funcional Aprovadas. Diário Oficial [da] Republica Federativa do Brasil, Brasília, jul. 2008.

BRUN-GRAEPPI, A. K. A. S. et al. Cell microcarriers and microcapsules of stimuli-responsive polymers. Journal of Controlled Release, v. 149, p. 209-224, 2011.

BURGAIN, J.; GAIANI, C.; SCHER, M. L. Encapsulation of probiotic living cells: From laboratory scale to industrial applications. Journal of Food Engineering, v. 104, p. 467-483, 2011.

BURTON-FREEMAN, B. Dietary fiber and energy regulation. The Journal of Nutrition, $\mathrm{p}$. 272-275, 2000.

CARDARELLI, H. R. Desenvolvimento de queijo 'petit-suisse' simbiótico. São Paulo: Programa de Pós-Graduação em Tecnologia BioquímicoFarmacêutica da Universidade de São Paulo, 2006. 133 p.

CARMO, A. F. S. Propriedades funcionais da biomassa e farinha de banana verde. $2015.58 \mathrm{f}$. Monografia (Graduação do Curso de Engenharia Bioquímica) - Escola de Engenharia de Lorena da Universidade de São Paulo, Lorena, 2015. Disponível em: <http://sistemas.eel.usp.br/
bibliotecas/monografias/2015/MBI15005.pdf>. Acesso em: 20 abril 2017.

CARRARA, C. L. et al. Uso da semente de linhaça como nutracêutico para prevenção e tratamento da aterosclerose. Revista Eletrônica de Farmácia, v. 6, p. 1-9, 2009.

CHAVARRI, M. et al. Microencapsulation of a probiotic and prebiotic in alginate-chitosan capsules improves survival in simulated gastrointestinal conditions. International Journal of Food Microbiology, v. 142, p. 185-189, 2010.

COOK, M. T. et al. Microencapsulation of probiotics for gastrointestinal delivery. Journal of Controlled Release, v. 162, p. 56-67, 2012.

COPPOLA, M. M.; TURNES, C. G. Probióticos e resposta imune. Ciência Rural, v. 34, p. 1297. 1303, 2004.

DHINGRA, D. et al. Dietary fibre in foods: a review. Journal of Food Science and Technology, v. 49, p. 255-266, 2012.

FERREIRA, S. M. R. et al. Cookies sem glúten a partir da farinha de sorgo. Archivos Latinoamericanos de Nutricion, v. 59, n. 4, p. 433-440, 2009.

GIBSON, G. R. et al. Dietary modulation of the human colonic microbiota: updating the concept of prebiotics. Nutrition Research Reviews, v. 17, p. 259-275, 2004.

GRANATO, D. et al. Probiotic Dairy Products as Functional Foods. Comprehensive Reviews in Food Science and Food Safety, v. 9, p. 455-457, 2010.

GRIZARD, D.; BARTHOMEUF, C. Non-digestible oligosaccharides used as prebiotic agents: mode of production and beneficial effects on animal and human health. Reprodução e Nutrição, v. 39, p. 563-588, 1999.

GUTKOSKI, L. C. et al. Desenvolvimento de barras de cereais à base de aveia com alto teor de fibra alimentar. Food Science and Technology, v. 27, p. 355-363, 2007.

HUQ, T. et al. Encapsulation of probiotic bacteria in biopolymeric system. Encapsulation of Probiotic Bacteria in Biopolymeric System. 
Critical Reviews in Food Science and Nutrition, v. 53, p. 909-916, 2013.

IBAÑES, E.; CIFUENTES, A. Benefits of using algae as natural sources of functional ingredients. Journal of the Science of Food and Agriculture, v. 93, p. 703-709, 2013.

INSTITUTE OF MEDICINE. Dietary reference intakes: energy, carbohydrate, fiber, fat, fatty acids, cholesterol, protein, and amino acids. Washington: National Academies Press, 2005.

KARAM, L. B.; GROSSMANN, M. V. E.; SILVA, R. R. S. F. Misturas de farinha de aveia e amido de milho com alto teor de amilopectina para produção de "snacks". Food Science and Technology, v. 21, p. 158-163, 2001.

KARKOW, F. J. A.; FAINTUCH, J.; KARKOW, A. G. M. Probióticos: perspectivas médicas. $A M R I G S$, v. 51, p. 38-48, 2007.

KRASAEKOOPT, W.; BHANDARI, B.; DEETH, $\mathrm{H}$. Evaluation of encapsulation techniques of probiotics for yoghurt. International Dairy Journal, v. 13, p. 3-13, 2003.

LI, X. Y. et al. Preparation of alginate/chitosan/ carboxymethyl chitosan complex microcapsules and application in Lactobacillus casei ATCC 393. Carbohydrate Polymers, v. 83, p. 1479-1485, 2011.

MACEDO, M. C. C. et al. Elaboração de pães formulados com farinhas de sorgo, semente de abóbora, trigo e aveia. In: XXV CONGRESSO BRASILEIRO DE CIÊNCIA E TECNOLOGIA DE ALIMENTOS, 25., 24-28 out. 2016, Gramado. Anais... Porto Alegre: sbCTA-RS, 2016. Disponível em: $<$ http://www.ufrgs.br/sbctars-eventos/xxvcbcta/ anais/files/860.pdf $>$. Acesso em: 20 abril 2017.

MANDAL, S.; HATI, S. Microencapsulation of bacterial cells by emulsion technique for probiotic application. Methods in Molecular Biology, v. 1479, p. 273-279, 2016.

MARTINS, F. S. et al. Estudo do potencial probiótico de linhagens de Saccharomyces cerevisiae através de testes in vitro. Revista de Biologia e Ciências da Terra, v. 5, n. 2, 1-13, 2005.

MATTA, C. M. B. et al. Influência de prebióticos e de farinha integral de aveia na sobrevivência de bactérias probióticas em bebida simbiótica à base de arroz. Alimentos e Nutrição Araraquara, v. 23, p. 55-63, 2012.

MEDEIROS, M. J. et al. Composição química de misturas de farinhas de banana verde com castanha-do-brasil. Revista do Instituto Adolfo Lutz, v. 69, p. 396-402, 2010.

MENEZES, C. R. et al. Microencapsulação de probióticos: avanços e perspectivas. Ciência Rural, v. 43, n. 7, p. 1309-1316, 2013. Disponível em: <http://www.scielo.br/pdf/cr/2013nahead/ a18613cr2012-0763.pdf>. Acesso em: 31 jan. 2017.

MONTEIRO, S. Z. Utilização de mesclas de farinhas de arroz, inhame e quinoa na elaboração de disco de pizza pré assado sem glúten e sem lactose. 2013. 83 f. Trabalho de Conclusão (Curso de Engenharia de Alimentos) - Universidade Federal do Rio Grande do Sul, Porto Alegre, 2013. Disponível em: <http://www.lume.ufrgs. br/bitstream/handle/10183/87552/000910320. pdf? sequence $=1>$. Acesso 31 de jan 2017 .

MORAES, F. P.; COLLA, L. M. Alimentos funcionais e nutracêuticos: definições, legislação e benefícios à saúde. Revista Eletrônica de Farmácia, v. 3, p. 109-122, 2006.

MORAIS, M. B.; JACOB, C. M. A. O papel dos probióticos e prebióticos na prática pediátrica. Jornal de Pediatria, v. 82, p. 189-197, 2006.

NETTO, C. C. Avaliação das características morfológicas e dos marcadores bioquímicos relacionados à homeostase do tecido ósseo de ratas idosas suplementadas com diferentes tipos de prebióticos. 2009. 197 f. Tese (Doutorado) - Faculdade de Engenharia de Alimentos, Universidade Estadual de Campinas, Campinas, 2009. Disponível em: <http://unicamp.sibi.usp.br/ handle/SBURI/4113>. Acesso em: 31 jan. 2017.

O'SUllivan, M. G. et al. Probiotic bacteria: myth or reality? Food Science and Technology, v. 31, p. 309-314, 1992.

OLIVEIRA, A. R. A. Estudos de formulação em encapsulação de probióticos: experiência profissionalizante na vertente de farmácia comunitária, hospitalar e investigação. 2013. 122 f. Dissertação (Mestrado em Ciências Farmacêuticas) - Universidade da Beira Interior, 
Covilhã, 2013. Disponível em: $<$ http://ubibliorum. ubi.pt/handle/10400.6/4045>. Acesso em: 31 jan. 2017.

OLIVEIRA, K. G. et al. Estabilidade de antocianinas durante o armazenamento de farinha de sorgo. In: V SIMPÓSIO DE SEGURANÇAALIMENTAR, 5., 26-29 maio 2015, Bento Gonçalves. Anais.. Porto Alegre: sbCTA-RS, 2015. Disponível em: $<$ http://www.ufrgs.br/sbctars-eventos/gerenciador/ painel/trabalhosversaofinal/SAL186.pdf $>$. Acesso em: 31 jan. 2017.

OLIVEIRA, N. M. Encapsulamento de Bifidobacterium lactis e a sua tolerância a fluidos do trato gastrointestinal. 2011. $52 \mathrm{f}$. Trabalho de Conclusão de Curso (Graduação em Nutrição) - Universidade Federal de Pernambuco, Vitória de Santo Antão, 2011. Disponível em: <https:// repositorio.ufpe.br/handle/123456789/18243>. Acesso em: 31 jan. 2017.

OUWEHAND, A. C., SALMINEN, S. ISOLAURI, E. Probiotics: an overview of beneficial effects. Antonie van Leeuwenhoek, v. 82, p. 279-289, 2002.

PINTO, S. S. et al. Effects of the addition of microencapsulated Bifidobacterium BB-12 on the properties of frozen yogurt. Journal of Food Engineering, v. 111, p. 563-569, 2013.

PUUPPONEN-PIMIA, R. et al. Development of functional ingredients forgut health. Trends in Food Science \& Technology, v. 13, p. 3-11, 2002.

QUEIROZ, V. A. V. et al. O sorgo na alimentação humana. Sete Lagoas: Embrapa Milho e Sorgo, 2009. Ministério da Agricultura Pecuária e Abastecimento. Circular Técnica, 133. Disponível em: <http://www.agencia.cnptia.embrapa.br/ Repositorio/Circ+133 000gd1q62zq02wx5ok0 rofsmqcc098ea.pdf>. Acesso em: 02 fev. 2017.

RAMOS, P. D.; LEONEL, M.; LEONEL, S. Amido resistente em farinhas de banana verde. Alimentos e Nutrição Araraquara, v. 20, p. 479483, 2009.

RANIERI, L. M.; DELANI, T. C. O. Banana verde (Musa spp): obtenção da biomassa e ações fisiológicas do amido resistente. Revista Uningá, v. 20, p. 43-49, 2014.
RAUD, C. Os alimentos funcionais: a nova fronteira da indústria alimentar análise das estratégias da danone e da nestlé no mercado brasileiro de iogurtes. Revista de Sociologia e Politica, v. 16, p. 85-100, 2008.

REIS, J. M. C. et al. Informação tecnológica relacionada aos pré e probióticos com base no registro das patentes: o que há de novo? Arquivos Brasileiros de Cirurgia Digestiva, v. 29, p. 279281, 2016.

SAAD, S. M. Y. Probióticos e prebióticos: o estado da arte. Brazilian Journal of Pharmaceutical Sciences, v. 42, p. 1-16, 2006.

SILVA, P. T. et al. Avaliação do efeito da adição de microcápsulas probióticas às características físico-químicas, microbiológicas e sensoriais de salame tipo italiano. In: XII LATIN AMERICAN CONGRESS ON FOOD MICROBIOLOGY AND HYGIENE, 12., 12-15 out. 2014, Foz do Iguaçu. Proceedings... São Paulo: Blucher, 2014. p. 227-228.

SILVA, P. T. et al. Microencapsulação de probióticos por spray drying: avaliação da sobrevivência sob condições gastrointestinais simuladas e da viabilidade sob diferentes temperaturas de armazenamento. Ciência Rural, v. 45, n. 7 , p. 1342-1347, 2015a. Disponível em: <http:// www.scielo.br/pdf/cr/2015nahead/1678-4596cr-0103_8478cr20140211.pdf>. Acesso em: 16 jun. 2017.

SILVA, T. M. et al. Coacervação complexa: uma técnica para a encapsulação de probióticos. Ciência e Natura, v. 37, p. 49-55, 2015 b.

SIMEONI, C. P. et al. Microencapsulação de probióticos: inovação tecnológica na indústria de alimentos. Revista do Centro do Ciências Naturais e Exatas, v. 18, p. 66-75, 2014. Disponível em: <https://periodicos.ufsm.br/reget/article/ download/13020/pdf $>$. Acesso em: 25 jan. 2017.

SIRÓ, I. et al. Functional food. Product development, marketing and consumer acceptance - a review. Appetite, v. 51, p. 456-467, 2008.

SOUZA, A. F. 2015, Estudo da viabilidade de microrganismos probióticos encapsulados em matriz polimérica natural contendo ingredientes prebióticos e fibras alimentares. 205. 106 p. Tese 
(Doutorado em Ciências) - Escola de Engenharia de Lorena, Universidade de São Paulo, Lorena, 2015.

VIDAL, A. M. et al. A ingestão de alimentos funcionais e sua contribuição para a diminuição da incidência de doenças. Cadernos de Graduação - Ciências Biológicas e da Saúde, v. 1, p. 43-52, 2012.

WALTER, M.; MARCHEZAN, E.; AVILA, L.A. Arroz: composição e características nutricionais. Ciência Rural, v. 38, p. 1184-1192, 2008.

ZAMMORA-VEGA, R. et al. Effect of incorporating prebiotics in coating materials for the microencapsulation of Sacharomyces boulardii. International Journal of Food Sciences and Nutrition, v. 63, p. 930-935, 2012.

ZAPATA, J. E. M.; QUINTERO, O. A. C.; PORRAS, L. D. B. Sorption isotherms for oat flakes (avena sativa 1.). Agronomia Colombiana, v. 32, p. 52-58, 2014.

ZERAIK, M. L. et al. Maracujá: um alimento funcional? Brazilian Journal of Pharmacognosy, v. 20, p. 459-471, 2010.

ZOU, Q. et al. Microencapsulation of Bifidobacterium bifidum F-35 in reinforced alginate microspheres prepared by emulsification / internal gelation. International Journal of Food Science \& Technology, v. 46, p. 1672-1678, 2011. 